Pacific Journal of Mathematics

A NOTE ON REFLEXIVE MODULES 


\section{A NOTE ON REFLEXIVE MODULES}

\section{E. E. ENOCHS}

For any ring $A$ and left (resp. right) $A$-module $E$ we let $E^{*}$ denote the right (resp. left) $A$-module $\mathrm{Hom}_{4}\left(E, A_{s}\right)$ (resp. $\mathrm{Hom}_{A}\left(E, A_{d}\right)$ ) where $A_{s}$ (resp. $A_{d}$ ) denotes $A$ considered as a left (resp. right) $A$-module. Then the mapping $E \rightarrow E^{* *}$ such that $x \in E$ is mapped onto the mapping $\varphi \rightarrow \varphi(x)$ is linear.

Specker [3] has shown that if $E$ is a free $Z$-module with a denumerable base (where $Z$ denotes the ring of integers) then $E$ is reflexive, i.e. the canonical homomorphism $E \rightarrow E^{* *}$ is a bijection. In this paper it is shown that a free module $E$ with a denumerable base over a discrete valuation ring $A$ is reflexive if and only if $A$ is not complete and if and only if $E$ is complete when given the topology having finite intersections of the kernels of the linear forms as a fundamental system of neighborhoods of $O$. Specker's result can be deduced from these results. We note that this topology has been used and studied by Nunke [2] and Chase [1].

THEOREM 1. Let $A$ be a discrete valuation ring with prime II and let $E$ be a free $A$-module with a denumerable base. Then $E$ is reflexive if and only if $A$ is not complete.

Proof. Let $\left(a_{i}\right)_{i \in N}$ ( $N$ the set of natural numbers) be a base of $E$ and let $E_{j}=\left\{\varphi \mid \varphi \in E^{*}, \varphi\left(a_{i}\right)=0, i=0,1,2, \cdots, j-1\right.$. Let $a_{j}^{\prime} \in E^{*}$ be such that $a_{j}^{\prime}\left(a_{j}\right)=1, a_{j}^{\prime}\left(a_{k}\right)=0$ if $j \neq k$. Then clearly $a_{0}^{\prime}$, $a_{1}^{\prime}, \cdots \alpha_{j-1}^{\prime}$ generate a supplement of $E_{j}$ in $E^{*}$. For each $x \in E$ the canonical image of $x$ in $E^{* *}$ annihilates some $E_{j}$ and conversely if $\psi \in E^{* *}$ annihilates $E_{j}$ then $\psi$ is the canonical image of $\sum_{i=0,1, \ldots, j-1} \psi\left(a_{i}^{i}\right) a i$. Hence $E \rightarrow E^{* *}$ is a surjection if and only if each $\psi \in E^{* *}$ annihilates some $E_{j}$. If $E \rightarrow E^{* *}$ is not a surjection let $\psi \in E^{* *}$ be such that $\psi\left(E_{j}\right) \neq 0$ for each $j \in N$ and let $\varphi_{j} \in E_{j}$ be such that $\psi\left(\varphi_{j}\right) \neq 0$. We can suppose that $\varphi_{j} \in \Pi^{j} E_{j}$ and that $\psi\left(\varphi_{j}\right) \in \Pi_{j}^{m} A$ but $\psi\left(\varphi_{j}\right) \notin \Pi^{m_{j}+1} A$ where $m_{i+1}>m_{i}$ for all $i \in N$. To show $A$ complete it suffices to show that every series $\sum_{j \in N} \beta_{j} \Pi^{m j}, \beta_{j} \in A$ converges. We can find a scalar multiple of $\varphi_{j}$ say $\varphi_{j}^{\prime}$ such that $\psi\left(\varphi_{j}^{\prime}\right)=\beta_{j} \Pi_{j}^{m}$. Then let $\varphi \in E^{*}$ be such that $\varphi(x)=\sum_{j \in N} \varphi_{j}^{\prime}(x)$ for all $x \in E$. This sum is defined since for a fixed $x \in E$ and $M$ sufficiently large positive integer we have $\varphi_{\boldsymbol{M}+i}(x)=0$ for all $i \in N$. Furthermore, since $\varphi_{j}^{\prime} \in \Pi^{j} E_{j}$ it is clear that the series $\sum \varphi_{j}^{\prime}$ converges to $\varphi$ when $E^{*}$ is given the topology having

Received December 6, 1963. 
the submodules $\Pi^{n} E^{*}, n \in N$ as a fundamental system of neighborhoods of 0 . Under this topology $\psi: E^{*} \rightarrow A$ is continuous. Hence

$$
\sum_{j \in N} \psi\left(\varphi_{j}^{\prime}\right)=\sum_{j \in N} \beta_{j} \Pi^{m} j
$$

converges to $\psi(\varphi)$. Thus $A$ is complete.

Conversely if $A$ is complete let $\left(a_{i}^{\prime}\right)_{i \in N}$ as defined above be a subfamily of the family $\left(a_{i}^{\prime}\right)_{i \in N_{1}}, N_{1} \supset N$ where $\left(a_{i}^{\prime}+\Pi E^{*}\right)_{i \in N_{1}}$ is a base of the $A / \Pi A$ module $E^{*} / \Pi E^{*}$. Then if $E^{\prime}$ is the submodule of $E^{*}$ generated by the family $\left(a_{i}^{\prime}\right)_{i \in N_{1}}$ it is easy to see that $E^{\prime}$ is free with base $\left(a_{i}^{\prime}\right)_{i \in N_{1}}$ and that $E^{\prime}$ is a dense pure submodule of $E^{*}$, i.e. $E^{*} / E^{\prime}$ is divisible and torsion free. Then, since $A$ is complete the map $E^{* *} \rightarrow$ $E^{\prime *}$ which maps an element of $E^{* *}$ onto its restriction to $E^{\prime}$ is a bijection. But this clearly implies the existence of a $\psi \in E^{* *}$ such that $\psi\left(a_{i}^{\prime}\right) \neq 0$ for all $i \in N_{1}$ and hence for all $i \in N$. Thus $E \rightarrow E^{* *}$ is not a surjection.

COROLlaRY. If $A$ is an integral domain with a prime $\Pi$ such that the discrete valuation ring $A_{\pi}$ is not complete then free A-modules with denumerable bases are reflexive.

Proof. There exist canonical injections of $E, E^{*}$ and $E^{* *}$ in $E_{\pi}$, $E_{\pi}^{*}$, and $E_{\pi}^{* *}$ and furthermore if for $x \in E, \varphi \in E^{*}$, and $\psi \in E^{* *}$ we let $\bar{x}, \bar{\varphi}$, and $\bar{\psi}$ denote the image of $x, \varphi$, and $\psi$ in $E_{\pi}, E_{\pi}^{*}$, and $E_{\pi}^{* *}$ then $\varphi(x)=\bar{\varphi}(\bar{x})$ and $\psi(\varphi)=\bar{\psi}(\bar{\varphi})$. Then if $\left(a_{i}\right)_{i \in N}$ is a base of $E$, $\left(\bar{a}_{i}\right)_{i \in N}$ is a base of $E_{\pi}$ and if $\left(a_{i}^{\prime}\right)_{i \in N}$ is defined as above we get $\bar{a}_{i}^{\prime}\left(\bar{a}_{i}\right)=1$, $\bar{a}_{i}^{\prime}\left(\bar{a}_{j}\right)=0$ if $i \neq j$. Then if $\psi \in E^{* *}$ is such that $\psi\left(E_{j}\right)=0$ for each $j$ then $\bar{\psi}$ is not in the image $E_{\pi}$ under the canonical homomorphism since $\bar{\psi}\left(\left(E_{\pi}\right)_{j}\right) \neq 0$ where $E_{j}$ and $\left(E_{\pi}\right)_{j}$ are defined as above.

THEOREM 2. If $A$ is a left Noethrian hereditary ring, then a left $A$ module $E$ is reflexive if and only if $E$ is complete when endowed with the topology having the finite intersections of the kernels of the linear forms as a fundamental system neighborhoods of 0.

Proof. Clearly $E$ is separated with the topology described in the theorem if and only if the map $E \rightarrow E^{* *}$ is an injection hence we suppose that $E$ is separated. For each finite subset $X$ of $E^{*}$ consider the subset $X^{\circ}$ of $E^{* *}$ consisting of all $\psi \in E^{* *}$ such that $\psi(X)=0$. Let $E^{* *}$ be endowed with the topology having the submodules $X^{\circ}$ as a fundamental system of neighborhoods of 0 where $X$ ranges through all finite subsets of $E^{*}$. Then it is immediate that $E^{* *}$ is complete with this topology. If we can establish that the canonical map $E \rightarrow$ $E^{* *}$ maps $E$ isomorphically onto a dense subset of $E^{* *}$ then it will 
follow immediately that $E$ is complete if and only if $E$ is reflexive.

Let $X$ be a finite subset of $E^{*}$. Then clearly the intersection of the kernels of the elements in $X$ is mapped onto the intersection of $X^{\circ}$ with the canonical image of $E$ in $E^{* *}$ hence $E$ is mapped isomorphically onto a subset of $E^{* *}$. Thus it only remains to prove that the image of $E$ in $E^{* *}$ is dense in $E^{* *}$. If $\psi \in E^{* *}$ and $X=\left\{\varphi_{1}, \varphi_{2}, \cdots \varphi_{n}\right\}$ is a finite set of elements of $E^{*}$ consider the map $E \rightarrow \prod_{i=1, \ldots, n} A_{i}$ such that $x \rightarrow\left(\varphi_{i}(x)\right)_{i=1, \ldots, n}$ where $A_{i}=A_{s}$. Since $A$ is left hereditary the kernel of this map $E_{1}=\bigcap_{i=1, \ldots, n} \varphi_{i}^{-1}(0)$ is a direct summand of $E$ so let $E=E_{1}+E_{2}$ (direct). Then since $A$ is left Noetherian $E_{2}$ is a finitely generated projective module so it is relfexive. Now $E^{*}=$ $E_{i}^{\circ}+E_{2}^{\circ}$ (direct) and $E^{* *}=E_{1}^{\circ \circ}+E_{2}^{\circ \circ}$ (direct). Clearly $E_{2}^{\circ \circ}$ is isomorphic to $E_{2}^{* *}$ and the restriction of the canonical homomorphism $E \rightarrow E^{* *}$ maps $E_{2}$ isomorphically onto $E_{2}^{\circ \circ}$. If $\psi=\psi_{1}+\psi_{2}$ where $\psi_{1} \in E_{1}^{\circ \circ}$ let $x \in E_{2}$ be such that $x \rightarrow \psi_{2}$ under the map $E \rightarrow E^{* *}$. Then since $\psi-\psi_{2} \in E_{1}^{\circ \circ}$ and since $X=\left\{\varphi_{1}, \varphi_{2}, \cdots, \varphi_{n}\right\} \subset E_{1}^{\circ}$ we get $\psi-\psi_{2} \in X^{\circ}$. This completes the proof.

\section{REFERENCE}

1. S. Chase, Function topologies on Abelian groups, Illionois J. of Math., 7 (1963), .593-608.

2. R. J. Nunke, On direct products of infinite cyclic groups, Proc. Amer. Math. Soc., 13 (1962), 66-71.

3. E. Specker, Additive gruppen von Folgen ganzer zahlen, Protugaliae Math., (1950), 131-140.

UNIVERSITY OF SOUTH CAROLINA 



\section{PACIFIC JOURNAL OF MATHEMATICS}

\section{EDITORS}

\author{
Robert Osserman \\ Stanford University \\ Stanford, California
M. G. Arsove
University of Washington
Seattle 5 , Washington

\author{
J. DugundJI \\ University of Southern California \\ Los Angeles 7, California
}

Lowell J. Paige

University of California

Los Angeles 24, California

\section{ASSOCIATE EDITORS}
E. F. BECKENBACH
B. H. NeumanN
F. WOLF
K. YOSIDA

\section{SUPPORTING INSTITUTIONS}

\author{
UNIVERSITY OF BRITISH COLUMBIA \\ CALIFORNIA INSTITUTE OF TECHNOLOGY \\ UNIVERSITY OF CALIFORNIA \\ MONTANA STATE UNIVERSITY \\ UNIVERSITY OF NEVADA \\ NEW MEXICO STATE UNIVERSITY \\ OREGON STATE UNIVERSITY \\ UNIVERSITY OF OREGON \\ OSAKA UNIVERSITY \\ UNIVERSITY OF SOUTHERN CALIFORNIA
}

\author{
STANFORD UNIVERSITY \\ UNIVERSITY OF TOKYO \\ UNIVERSITY OF UTAH \\ WASHINGTON STATE UNIVERSITY \\ UNIVERSITY OF WASHINGTON \\ * * * * \\ AMERICAN MATHEMATICAL SOCIETY \\ CALIFORNIA RESEARCH CORPORATION \\ SPACE TECHNOLOGY LABORATORIES \\ NAVAL ORDNANCE TEST STATION
}

Mathematical papers intended for publication in the Pacific Journal of Mathematics should by typewritten (double spaced), and on submission, must be accompanied by a separate author's résumé. Manuscripts may be sent to any one of the four editors. All other communications to the editors should be addressed to the managing editor, L. J. Paige at the University of California, Los Angeles 24, California.

50 reprints per author of each article are furnished free of charge; additional copies may be obtained at cost in multiples of 50 .

The Pacific Journal of Mathematics is published quarterly, in March, June, September, and December. Effective with Volume 13 the price per volume (4 numbers) is $\$ 18.00$; single issues, $\$ 5.00$. Special price for current issues to individual faculty members of supporting institutions and to individual members of the American Mathematical Society: $\$ 8.00$ per volume; single issues $\$ 2.50$. Back numbers are available.

Subscriptions, orders for back numbers, and changes of address should be sent to Pacific Journal of Mathematics, 103 Highland Boulevard, Berkeley 8, California.

Printed at Kokusai Bunken Insatsusha (International Academic Printing Co., Ltd.), No. 6, 2-chome, Fujimi-cho, Chiyoda-ku, Tokyo, Japan.

PUBLISHED BY PACIFIC JOURNAL OF MATHEMATICS, A NON-PROFIT CORPORATION

The Supporting Institutions listed above contribute to the cost of publication of this Journal, but they are not owners or publishers and have no responsibility for its content or policies. 


\section{Pacific Journal of Mathematics}

\section{Vol. 14, No. $3 \quad$ July, 1964}

Erik Balslev and Theodore William Gamelin, The essential spectrum of a class of ordinary differential operators . . . . . . . . . . . . . . . . . . . .

James Henry Bramble and Lawrence Edward Payne, Bounds for derivatives in

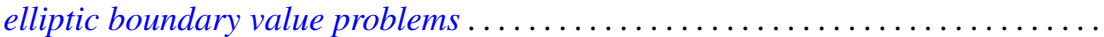

Hugh D. Brunk, Integral inequalities for functions with nondecreasing

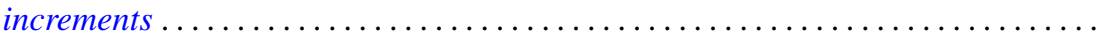

William Edward Christilles, A result concerning integral binary quadratic

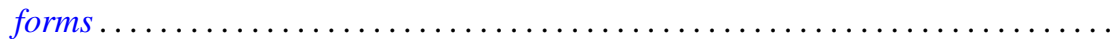

Peter Crawley and Bjarni Jónsson, Refinements for infinite direct decompositions of

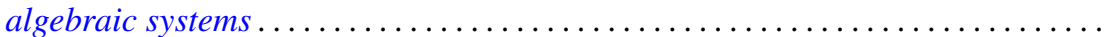

Don Deckard and Carl Mark Pearcy, On continuous matrix-valued functions on a Stonian space.

Raymond Frank Dickman, Leonard Rubin and P. M. Swingle, Another

characterization of the $n$-sphere and related results $\ldots \ldots \ldots \ldots \ldots \ldots$

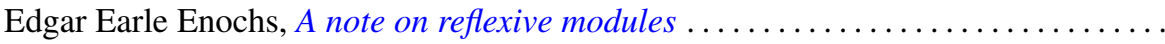

Vladimir Filippenko, On the reflection of harmonic functions and of solutions of the

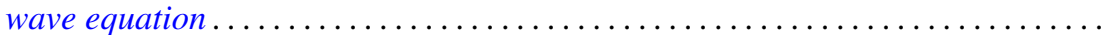

Derek Joseph Haggard Fuller, Mappings of bounded characteristic into arbitrary

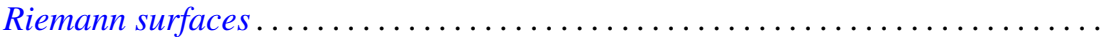
895

Curtis M. Fulton, Clifford vectors . . . . . . . . . . . . . . . . . . . . . . . . . . . . . . 917

Irving Leonard Glicksberg, Maximal algebras and a theorem of Radó . .

919

Kyong Taik Hahn, Minimum problems of Plateau type in the Bergman metric

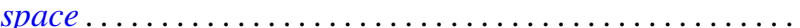

A. Hayes, A representation theory for a class of partially ordered rings...

J. M. C. Joshi, On a generalized Stieltjes trasform

J. M. C. Joshi, Inversion and representation theorems for a generalized Laplace transform ...

Eugene Kay McLachlan, Extremal elements of the convex cone $B_{n}$ of functions ...

Robert Alan Melter, Contributions to Boolean geometry of p-rings ...

James Ronald Retherford, Basic sequences and the Paley-Wiener criterion . . . . . . . 1019

Dallas W. Sasser, Quasi-positive operators. .

Oved Shisha, On the structure of infrapolynomials with prescribed coefficients ..

Oved Shisha and Gerald Thomas Cargo, On comparable means

Maurice Sion, A characterization of weak ${ }^{*}$ convergence ........

Morton Lincoln Slater and Robert James Thompson, A permanent inequality for

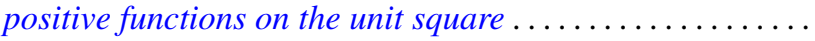

David A. Smith, On fixed points of automorphisms of classical Lie algebras ...

Sherman K. Stein, Homogeneous quasigroups ................

J. L. Walsh and Oved Shisha, On the location of the zeros of some infrapolynomials with prescribed coefficients .

Ronson Joseph Warne, Homomorphisms of $d$-simple inverse semigroups with identity . 